\title{
Preparation of Cellulose Nanocrystals Using Highly Recyclable Organic Acid Treated Softwood Pulp
}

\author{
Songlin Wang, ${ }^{\mathrm{a}, \mathrm{b}, *}$ Fei Wang, ${ }^{\mathrm{a}}$ Zongjia Song, ${ }^{\mathrm{a}}$ Xiaoming Song, ${ }^{\mathrm{a}}$ Xuxu Yang, ${ }^{\mathrm{a}}$ and Qian \\ Wang ${ }^{\text {a }}$
}

Cellulose nanocrystals (CNC) were successfully obtained from softwood pulp by p-toluenesulfonic acid ( $\mathrm{p}-\mathrm{TsOH}$ ) hydrolysis under the treatment of $\mathrm{p}$ - TsOH mass concentration of $60 \%$, temperature of $70{ }^{\circ} \mathrm{C}$, reaction time of $4 \mathrm{~h}$, and pulp to solution ratio of 1:20 ( $\mathrm{g} / \mathrm{mL})$. Zeta potential and dynamic light scattering (DLS), scanning electron microscopy (SEM), Xray diffraction (XRD), Fourier-transform infrared spectroscopy (FTIR), Xray photoelectron spectroscopy (XPS), and thermogravimetric analysis (TGA) were used to characterize the physical-chemical properties of the CNC. Under these conditions, the CNC exhibited good thermal stability in the suspension with a high crystallinity index of $90.1 \%$. The CNC had an average diameter of $4.87 \mathrm{~nm}$ and average length $175.5 \mathrm{~nm}$ with no undesired elemental contamination. The degradation temperature of the $\mathrm{CNC}$ was relatively high at $310^{\circ} \mathrm{C}$. Moreover, $\mathrm{p}-\mathrm{TsOH}$ was recovered by crystallization technology, and the recovery rate was over $70 \%$, providing an environmentally friendly way for the development of biomass materials.

Keyword: Softwood pulp; p-TsOH hydrolysis; Cellulose nanocrystals; Acid recovery

Contact information: a: College of Marine Science and Biological Engineering, Shandong Provincial Key Laboratory of Biochemical Engineering, Qingdao University of Science \& Technology, Qingdao,

Shandong 266042 China; $b$ : Key Laboratory of Pulp and Paper Science \& Technology of Ministry of

Education/Shandong Province, Qilu University of Technology, Jinan, Shandong 250353 China;

* Corresponding author: wangsongl@126.com

\section{INTRODUCTION}

Cellulose is the most abundant renewable natural polymer resource, with an annual production of 14 to 20 billion tons (Lima and Borsali 2004; Habibi et al. 2010). Cellulose is widely distributed in higher plants, algae, fungi, bacteria, and some lower animals. Regardless of the source, the structure of cellulose is shown in Fig. 1. The basic unit is the D-pyranose-glucose group, which is a linear polymer linked by $\beta$ - $(1,4)$-glycosidic bonds (Brinchi et al. 2013). Compared with synthetic polymer materials, cellulose has advantages of being renewable, degradable, non-toxic, and non-polluting. Cellulose is widely available at a low cost and, therefore, is an indispensable resource for society.

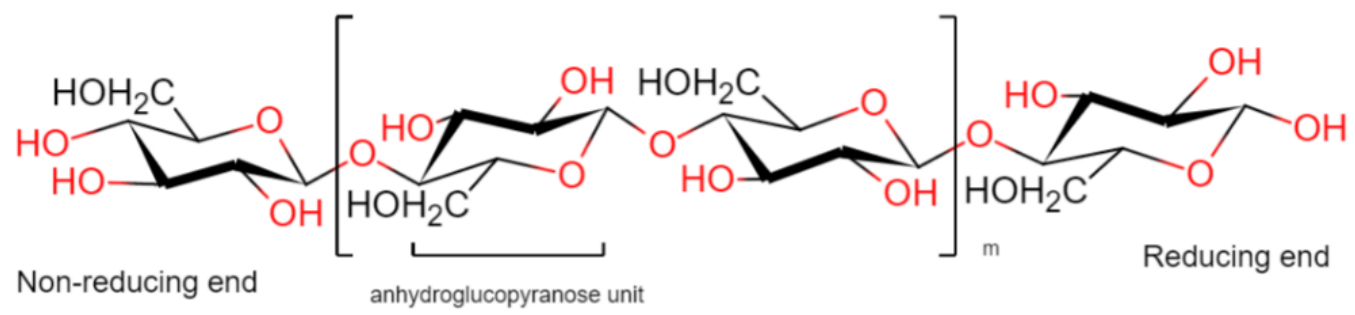

Fig. 1. Chemical structure of cellulose 
The geometrical size and morphology of cellulose has different effects on its utilization. In general, plant-derived nanocelluloses can be divided into two categories: cellulose nanofibers (CNF) and cellulose nanocrystals (CNC). CNC, with a diameter of 5 to $20 \mathrm{~nm}$ and a length of several hundred nanometers, have many excellent properties such as high surface area (Stelte and Sanadi 2009; Sandeep et al. 2014), high mechanical strength and stiffness, high modulus, high crystallinity, biodegradability, and good hydrophilicity. It can be used as a functional material in gels (Aulin et al. 2010; Dong et al. 2013; Zhang et al. 2018), optoelectronics (Miettunen et al. 2014; Zu et al. 2016; Xing et al. 2018), adsorbent materials (Fernandes et al. 2013; Lin and Dufresne 2014; Sol 2016; Seabra et al. 2017), and medical materials (Carlsson et al. 2012; Liu et al. 2015; Karim et al. 2016; Mishra et al. 2018). CNC can also be used as a nanofiller in film materials (Stelte and Sanadi 2009; Belbekhouche et al. 2011; Herrera et al. 2014; Sandeep et al. 2014; Guo et al. 2018) or as a reinforcing agent in composite materials (Samir et al. Dufresne 2005; Choi and Simonsen 2006; Chang et al. 2010; Dufresne 2013; Oksman et al. 2016). In recent years, the application of $\mathrm{CNC}$ has aroused widespread concern among researchers.

Most preparation methods for CNC include an acid hydrolysis method and an enzymatic method (Teixeira et al. 2015), in which the sulfuric acid method (Coelho et al. 2018; Theivasanthi et al. 2018; Maciel et al. 2019) is the most widely used. Acid hydrolysis releases a single crystallite by breaking the $\beta$-glycosidic bond of the amorphous region of cellulose, while the crystalline region maintains its integrity, producing $\mathrm{CNC}$ with high crystallinity of rod-like structure. The geometry of the CNC depends on the cellulose source and the acid hydrolysis treatment. The cellulose hydrolyzed is used to obtain CNC, and the hydroxyl groups on the cellulose surface is partially esterified to produce a negatively charged sulfate group. This helps the CNC suspension to have good dispersability (Tingaut et al. 2012). However, the sulfate group in the crystal reduces the thermal stability of the nanocellulose (Roman and Winter 2004). In addition, sulfuric acid is highly corrosive to equipment, and the recovery of sulfuric acid and the treatment of sulfate is still a huge challenge. Moreover, the recovery of sulfuric acid and the treatment of sulfate is still a great challenge. Compared with the inorganic acid hydrolysis method, the organic acid hydrolysis method has milder reaction conditions, less corrosiveness to equipment, relatively easier recovery of the organic acid, and environmentally friendly character.

Dicarboxylic acids have been used to prepare CNC (Bian et al. 2017). Carboxylated $\mathrm{CNC}$ has good thermal stability and solves the problem of acid recovery. However, as an organic acid, maleic acid is weak in acidity and insufficient degradation of cellulose results in low yield. The endoglucanase/ $\beta$-glucosidase has the function of catalyzing the $\beta$ glycosidic bond of the amorphous region of cellulose to promote hydrolysis, and it can advantageously adjust the size of the $\mathrm{CNC}$, which the reaction treatment was mild and can protect the cellulose from severe degradation. But since $\mathrm{CNC}$ obtained by enzymatic hydrolysis process does not have a surface negative charge, this results in poor stability of the suspension and longer enzymatic reaction time. Chen et al. (2016) used four organic acids (oxalic acid, maleic acid, p-toluenesulfonic acid, benzenesulfonic acid) to prepare CNC (Chen et al. 2016), but the relevant content of p-toluenesulfonic acid (p-TsOH) was very small. In this study, the preparation of $\mathrm{CNC}$ from $\mathrm{p}$-toluenesulfonic acid was considered in depth.

p-TsOH can be used for delignification and efficiently recovered by crystallization technology (Bian et al. 2017; Chen et al. 2017). Research on preparing CNC by hydrolysis with p-TsOH is very rare. In this study, $\mathrm{CNC}$ was successfully prepared by hydrolysis of a 
strong organic acid p-TsOH. Cellulose nanocrystals are characterized by DLS and zeta potentials, Zeta potential and dynamic light scattering (DLS), scanning electron microscopy (SEM), X-ray diffraction (XRD), Fourier-transform infrared spectroscopy (FTIR), X-ray photoelectron spectroscopy (XPS), and thermogravimetric analysis (TGA) to evaluate the physicochemical properties of CNC. The relatively low water solubility of p-TsOH, can be efficiently recovered by cooling the concentrated spent acid solution using crystallization technology.

\section{EXPERIMENTAL}

\section{Materials}

The p-TsOH was purchased from Tianjin Damao Chemical Reagent Factory (Tianjin, China), which was analytical grade and no further purification was required. The pulp board that was prepared from softwood was provided free of charge by Shandong Chenming Paper Group Co., Ltd. (Shandong, China).

\section{Methods}

Preparation of $\mathrm{CNC}$

A scheme for the preparation of CNC is shown in Fig. 2. The p-TsOH solution of desired mass concentration (50\% to $80 \%$ ) was prepared by adding the required amounts of $\mathrm{p}$-TsOH and $50 \mathrm{~mL}$ deionized water into a $150 \mathrm{~mL}$ flask. One hundred $\mathrm{mL}$ of acid solution and $5 \mathrm{~g}$ (oven-dry weight) of pulverized pulp (the solid-liquid ratio used in all treatments was 1:20 (g/ mL) was heated in a three-necked flask to $70^{\circ} \mathrm{C}$ and was treated for $4 \mathrm{~h}$ with continuous stirring at $200 \mathrm{rpm}$.

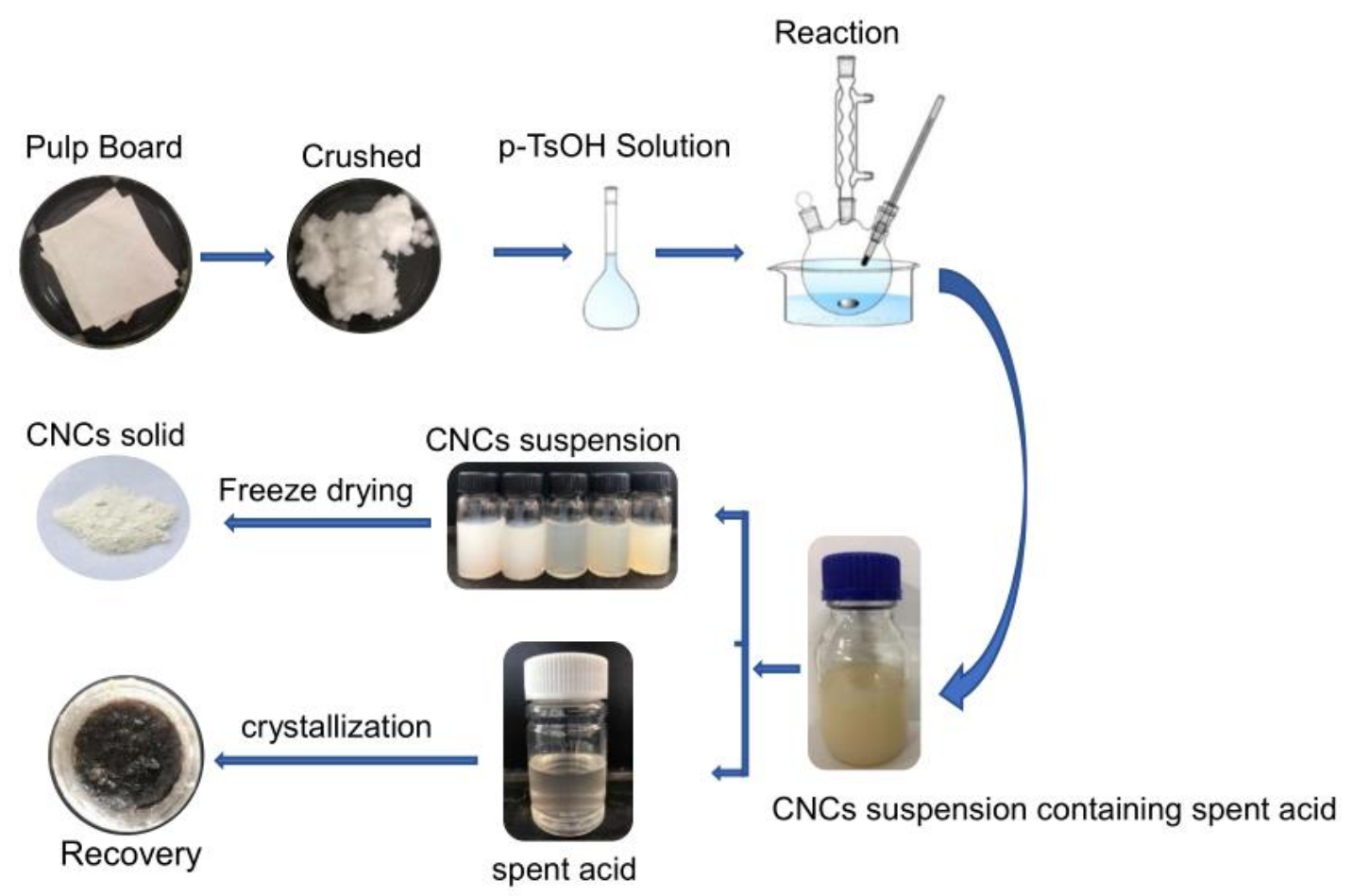

Fig. 2. A schematic process flow diagram illustrating the preparation of CNC by catalytic hydrolysis of $\mathrm{p}-\mathrm{TsOH}$ 
The reaction was stopped by adding $100 \mathrm{~mL}$ of deionized water $\left(25^{\circ} \mathrm{C}\right)$ into the flask. The sample obtained by acid hydrolysis was repeatedly washed by centrifugation (4000 rpm, 10 minutes) to remove the spent acid until the suspension was neutral. Then centrifugation was continued to separate the CNC (supernatant) from the hydrolyzed macromolecular cellulose (precipitation). The obtained suspension of CNC was freezedried to obtain a solid of CNC.

\section{Recovery of p-toluenesulfonic acid}

The spent acid was recovered by crystallization. The spent acid was concentrated using a rotary evaporator (RE-52CS, Shanghai, China) under the conditions of a vacuum of $-0.1 \mathrm{MPa}$ and a temperature of $50{ }^{\circ} \mathrm{C}$. The concentrated spent acid solution was transferred to a beaker and cooled at a rate of $1{ }^{\circ} \mathrm{C} / \mathrm{min}$. The crystal began to precipitate when the temperature reached $19.4{ }^{\circ} \mathrm{C}$. It was allowed to stand at this temperature for a period of time until the crystallization process had been completed. The precipitated crystals were separated from the spent acid solution by vacuum filtration, and the crystal mass was weighed to calculate the recovery of $\mathrm{p}-\mathrm{TsOH}$.

\section{Characterization}

Dynamically scattered light (DLS) and zeta potential

The CNC suspension was further dispersed by ultrasonic treatment and placed in an equipped colorimetric cuvette. The size and zeta potential of the CNC was measured using a particle size analyzer (Malvern Zetasizer Nano series, Malvern, UK). The measuring parameters are set on the computer, in which the material is protein, the dispersing medium is water, and the equilibrium time is $120 \mathrm{~s}$. The sample was cycled 3 times at $25{ }^{\circ} \mathrm{C}$ to obtain the average size and zeta potential of the sample.

\section{Scanning electron microscope (SEM)}

The cellulose of the pulp board and the obtained CNC image was observed and recorded using a scanning electron microscope (SEM) (JSM-6380, Jeol, Beijing, China) in order to analyze the morphology. All SEM samples mounted on a conductive aluminum plate were sputter coated with gold (Hitachi E-1010 Ion Sputtering System, Tokyo, Japan) for $90 \mathrm{~s}$ to provide sufficient conductivity under vacuum. At a current intensity of 1 to 2 $\mathrm{mA}$ and an accelerating voltage of $8 \mathrm{kV}$, the sample was imaged at a magnification of 140000 .

\section{Transmission electron microscope (TEM)}

Ten $\mu \mathrm{L}$ of the CNC suspension was deposited on a discharged carbon coated transmission electron microscope (TEM) grid, and excess liquid was absorbed using filter paper after $2 \mathrm{~min}$. The sample was stained with $2 \%$ phosphotungstic acid solution; then excess dye solution was removed using filter paper. The sample was dried at room temperature and observed using a transmission electron microscope (JEM-2100PLUS, Japan JEOL Company, Beijing, China) at an acceleration voltage of $200 \mathrm{kV}$.

\section{$X$-ray diffraction $(X R D)$}

Diffraction patterns of all the samples was obtained by an X-ray diffractometer (D/max-2500; Japan Science Co., Shanghai, China), operating at $40 \mathrm{kV}, 30 \mathrm{~mA}$, and CuKa radiation $(I=0.154 \mathrm{~nm})$. The sample was ground into a powder and spread on a sample plate, then gently pressed with a cover glass to scan the sample from $5^{\circ}$ to $60^{\circ}(2 \theta)$ at a rate 
of $5 \%$ min. The interplanar spacing of cellulose was calculated according to the Bragg's Law, and crystallinity index (CrI) was calculated according to Segal's empirical method (Segal et al. 1959),

$$
2 d \sin \theta=n \lambda
$$

where $\mathrm{d}$ is the interplanar spacing, $\theta$ is the Bragg angle, and $\lambda$ is the $\mathrm{X}$-ray wavelength.

$$
\operatorname{CrI}=\frac{I_{002}-I_{a m}}{I_{002}} \times 100
$$

In Eq. $2, I_{002}$ is the maximum intensity of diffraction of the lattice peak $2 \theta=22^{\circ}$ to $23^{\circ}$, and $I_{a m}$ is the minimum intensity of diffraction of the lattice peak at $2 \theta$ between $18^{\circ}$ and $19^{\circ}$.

\section{Fourier transform infrared spectroscopy (FTIR)}

The lyophilized CNC was analyzed for its chemical structure by Fourier transform infrared spectroscopy (FTIR) (VECTOR22; Germany Brooke Co., Ettlingen, Germany). Two mg of each sample was ground into a powder, and spectra were obtained at a resolution of $4 \mathrm{~cm}^{-1}$ in the range of 4000 to $450 \mathrm{~cm}^{-1}$ and averaged from 8 scans in transmission mode.

\section{$X$-ray photoelectron spectroscopy (XPS)}

The surface chemical changes of the $\mathrm{CNC}$ were analyzed by X-ray photoelectron spectroscopy (XPS) (ESCALAB Xi+ spectrometer, Thermo Fisher Scientific, Shanghai, China), in which the aluminum anode was operated at $150 \mathrm{~W}$, and a high-resolution spectrum was obtained by energy using a $0.1 \mathrm{eV}$ step and a $50 \mathrm{eV}$ analyzer to obtain a binding spectrum of carbon and oxygen.

\section{Thermogravimetric Analysis (TGA)}

The thermal stability of pulp fibrils and cellulose nanocrystals was analyzed by thermogravimetric analyzers (TAQ-500; Shimadzu Co., Kyoto, Japan). All samples were heated from $25{ }^{\circ} \mathrm{C}$ to $800{ }^{\circ} \mathrm{C}$ at a rate of $10{ }^{\circ} \mathrm{C} / \mathrm{min}$ under a nitrogen atmosphere (30 $\mathrm{mL} / \mathrm{min})$.

\section{RESULTS AND DISCUSSION}

Cellulose nanocrystals were successfully obtained by hydrolysis of p-TsOH under different concentrations, temperatures, and times. The yield of CNC and the content of degradation products in the spent acid were determined. To facilitate discussion, PxTytz indicated a mass concentration of $\mathrm{x} \%$, a reaction temperature of $\mathrm{y}{ }^{\circ} \mathrm{C}$, and a reaction time of $\mathrm{z}$ hours. As shown in Table 1, the yield of the CNC gradually increased as the concentration and/or temperature and/or time increases. This indicates that in the case of relatively harsh reaction conditions, the cellulose chain was sheared to a small size, and the degradation of cellulose was also aggravated. The yield of CNC under the treatment of P60T70t7 was the largest. Bian et al. (2017) used a dicarboxylic acid to produce nanocellulose. The yield was low at only a few percent, since maleic acid is a weak acid and incapable of sufficiently depolymerizing chemical pulp fibers. However, the p-TsOH used in this article is a strong acid which can fully depolymerize cellulose. 
Table 1. Yield of CNC and Content of Degradation Products under Different Treatment

\begin{tabular}{|c|c|c|c|}
\hline & Yield (\%) & Average Zeta $(\mathrm{mV})$ & Furfural $(\mathrm{mg} / \mathrm{mL})$ \\
\hline P50T50t4 & 5.21 & -11.8 & 0.5281 \\
\hline P50T70t4 & 9.86 & -13.3 & 1.583 \\
\hline P60T70t4 & 15.81 & -26.5 & 5.231 \\
\hline P70T70t4 & 16.40 & -21.5 & 5.367 \\
\hline P80T70t4 & 16.97 & -18.0 & 6.130 \\
\hline P60T70t2 & 9.32 & -18.5 & 2.753 \\
\hline P60T70t3 & 10.79 & -20.4 & 5.766 \\
\hline P60T70t5 & 21.5 & -17.3 & 5.890 \\
\hline P60T70t6 & 35.3 & -20.0 & 7.409 \\
\hline P60T70t7 & 40.1 & -17.5 & 13.859 \\
\hline P60T50t4 & 8.05 & -19.4 & 3.3347 \\
\hline P60T60t4 & 9.13 & -21.2 & 4.252 \\
\hline P60T80t4 & 16.42 & -13.1 & 6.982 \\
\hline
\end{tabular}

Note: For convenience of expression, PxTytz indicated a mass concentration of $x \%$, a reaction temperature of $\mathrm{y}^{\circ} \mathrm{C}$, and a reaction time of $z$ hours.

Different hydrolysis treatments exhibit different colours in $\mathrm{CNC}$ suspensions. The color arises because conjugated unsaturated structure carbonyl groups are produced, and these are chromophores (Yatagai and Zeronian 1994; Łojewska et al. 2007). The color of $\mathrm{CNC}$ gradually deepened as the concentration and time increased, as shown in Fig. 3. The change of color indicates that the degradation of cellulose is aggravated (Heggset $e t$ al. 2017; Coelho et al. 2018). After termination of the reaction, the color of the product was as shown in Fig. 3(a). Under milder hydrolysis treatments, the pale-yellow material of the product can be removed by sonication and multiple centrifugation cycles to obtain a bluish colloidal suspension. Cellulose was degraded to produce substances such as furfural. Furfural in the spent acid can be quantified by a UV spectrophotometer (TU-1810, Beijing General Instruments Co., Ltd. Beijing, China) with wavelengths of $284 \mathrm{~nm}$ (furfural). As shown in Table 1, the content of furfural in the spent acid was under more severe reaction conditions, indicating increased degradation of cellulose. As shown in Fig. 3(b), the color of the CNC suspension darkened, so the reaction temperature, concentration, and time should be controlled to prevent excessive degradation. Moreover, the spent acid was recovered by crystallization technology, and the recovery rate reached $71.8 \%$.

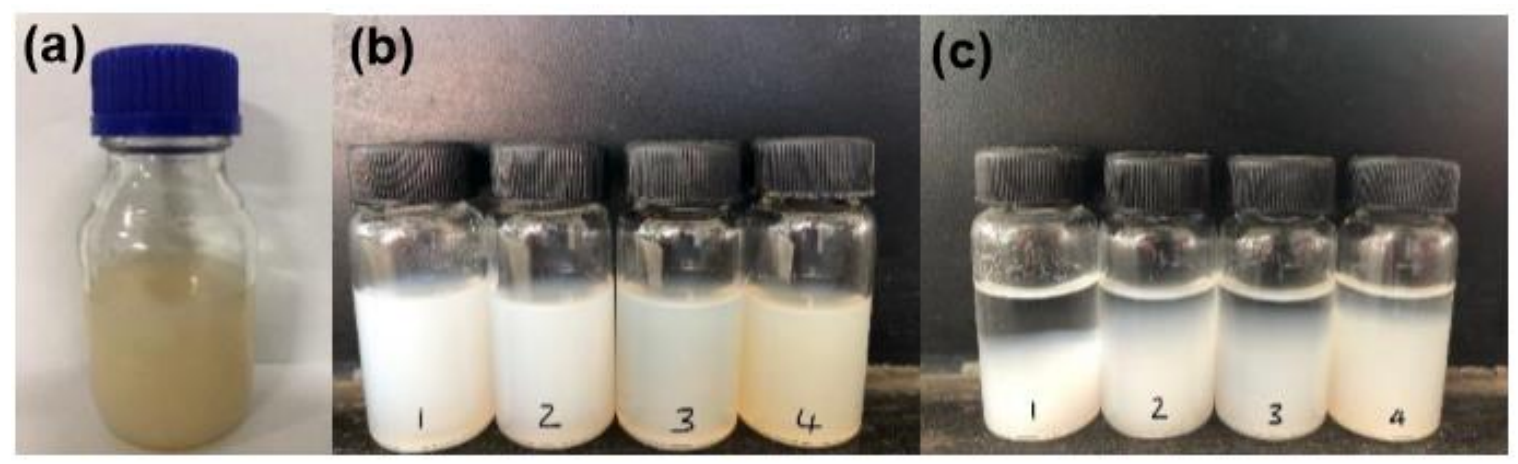

Fig. 3. CNC prepared under different hydrolysis conditions (where 1 is P50T50t4, 2 is P60T70t4, 3 is P70T70t4, 4 is P60T70t7) 
As shown in Fig. 3(c), noticeable stratification occurred in suspension of P50T50t4 after about 40 days, while weak stratification occurred in suspension of P60T70t4, P70T70t4, and P60T70t7. This phenomenon can be further explained by the zeta potential (५). For systems with negative power, the stability of the system is better under a larger value of $\zeta$. As shown in Table 1, the zeta potential of CNC ranged from $-26.5 \mathrm{mV}$ to -11.8 $\mathrm{mV}$. P60T70t4 had the largest absolute value of zeta potential, and the best stability of CNC suspension. With a zeta potential above $-25 \mathrm{mV}$, the suspension had good stability (Mirhosseini et al. 2008; Pereira et al. 2014). The hydrolysis process described herein was superior to the hydrochloric acid hydrolysis process in terms of suspension stability. The zeta potential of hydrochloric acid was $-16.9 \mathrm{mV}$ to $-12.2 \mathrm{mV}$ (Yu et al. 2013). However, compared with sulfuric acid and dicarboxylic acid hydrolysis, the suspension stability was relatively poor. The average potential of CNC prepared by sulfuric acid hydrolysis was above $-40 \mathrm{mV}$, and the average potential of CNC obtained by hydrolysis of dicarboxylic acid was $-30.9 \mathrm{mV}$ to $-46.8 \mathrm{mV}$ (Morais et al. 2013; Tian et al. 2016; Bian et al. 2017).

\section{Morphologies of CNC (DLS, SEM, and TEM)}

The morphologies of the CNC are important for its potential applications. Therefore, DLS, SEM, and TEM analyses of CNC were carried out to obtain the particle size distribution of $\mathrm{CNC}$, and the microscopic morphology of CNC was observed. In Fig. 4 , as the hydrolysis conditions became harsh, the particle size distribution of CNC moved toward a small size, probably because the $\beta$-glycosidic bond in cellulose broke and the long molecular chains of cellulose became short, which demonstrates that cellulose hydrolysis became more serious.

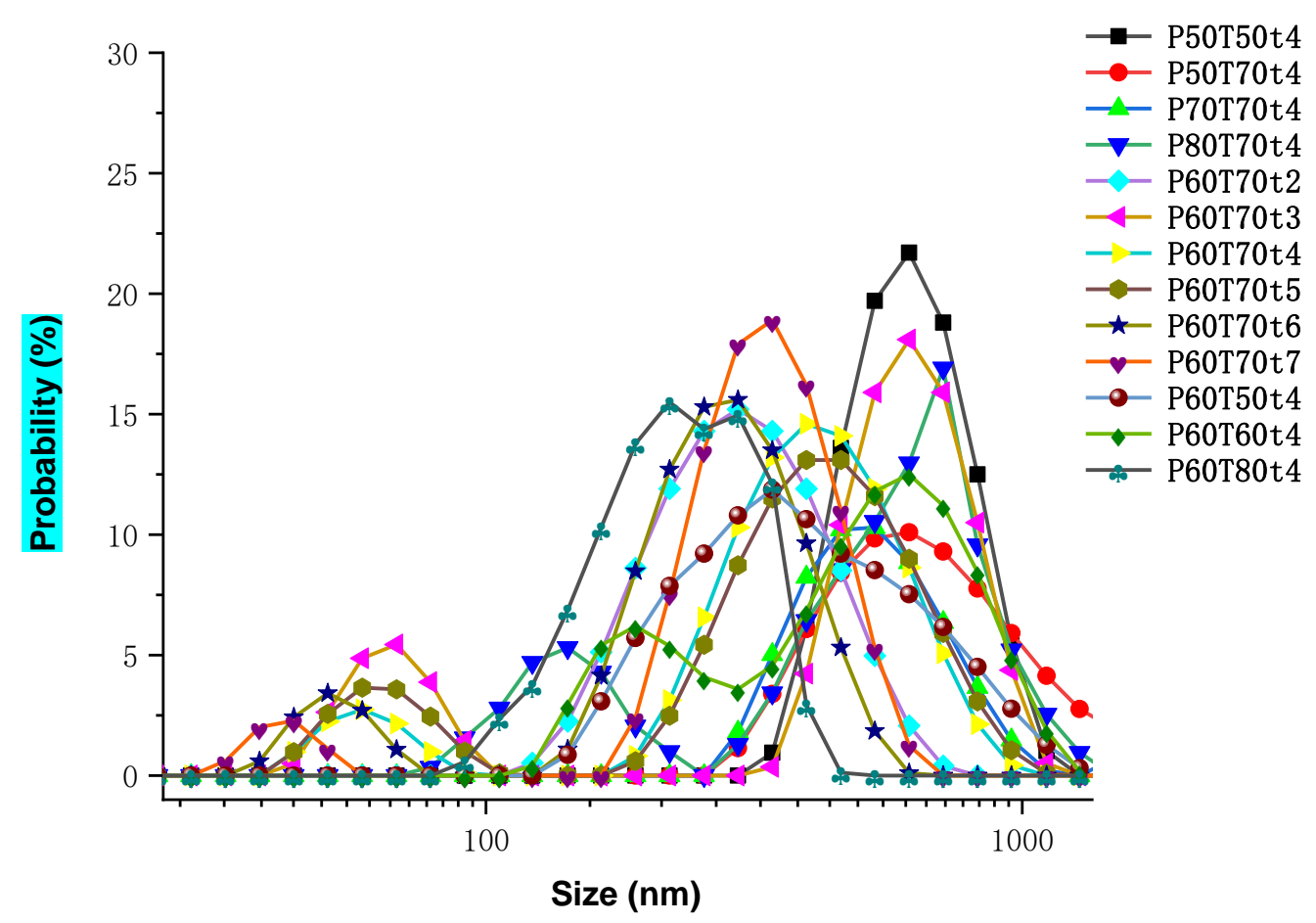

Fig. 4. Size distribution of CNC under different process conditions 
The shape of the CNC can be observed in Fig. 5(a,b). The rod-shaped and interwoven network structure made the CNC more flexible and mechanically strong (Liu et al. 2016). This was an important feature of $\mathrm{CNC}$ as a reinforcing agent in composite materials (Xu et al. 2013). The CNC underwent self-aggregation and self-assembly during the freeze-drying process, forming large-size cellulose by hydrogen bonding in the lateral and longitudinal directions. Moreover, the use of SEM for inspection required a gold spray operation, which also increased the size of the CNC. The resolution of the TEM is larger than that of the SEM, and the measurement does not need to require the gold-plating operation. It can better observe the true shape of the numerical control system and the size distribution of the CNC measured from the TEM photograph.

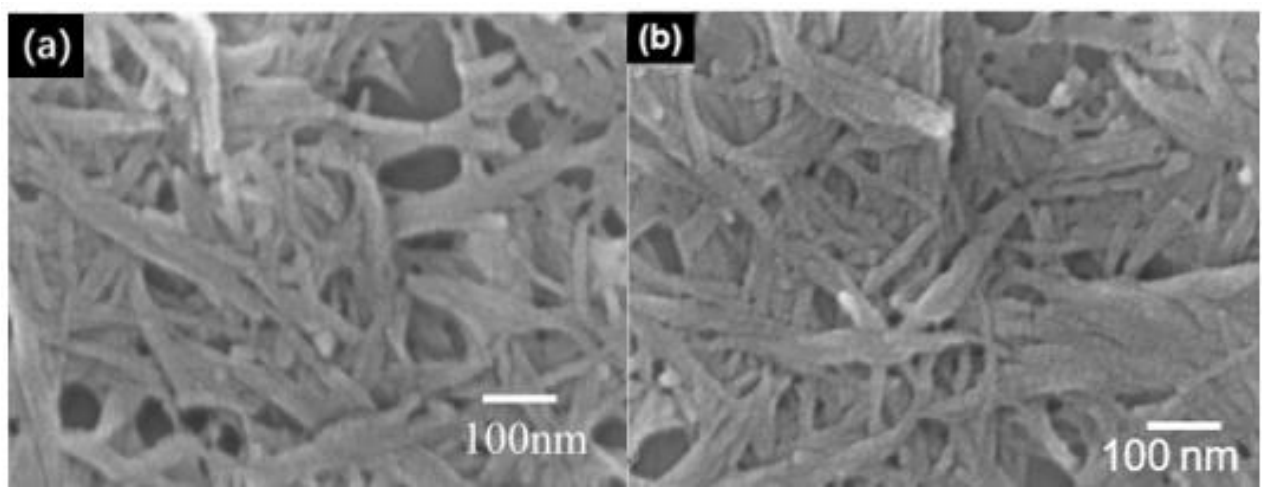

Fig. 5. SEM photographs of CNC obtained under P60T70t4(a) and P70T70t4(b)

The TEM image is shown in Fig. 6. The approximate contour of the intertwined $\mathrm{CNC}$ whiskers can be clearly seen, and the overlapped results in most CNC longitudinal and lateral dimensions are difficult to measure. Some fiber bundles with clear ends and lateral dimensions were selected for measurement.

(a)

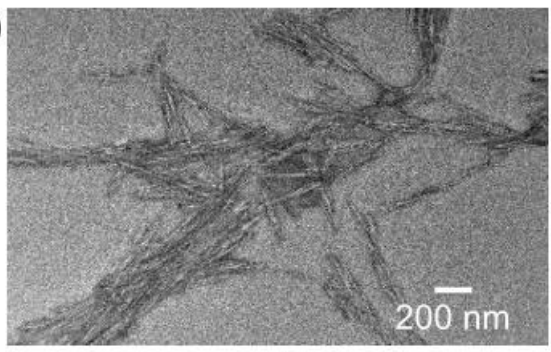

(b)

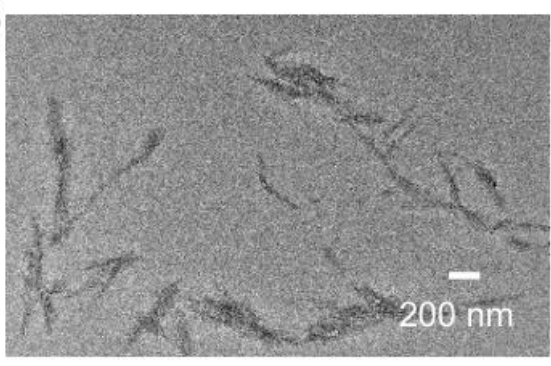

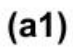
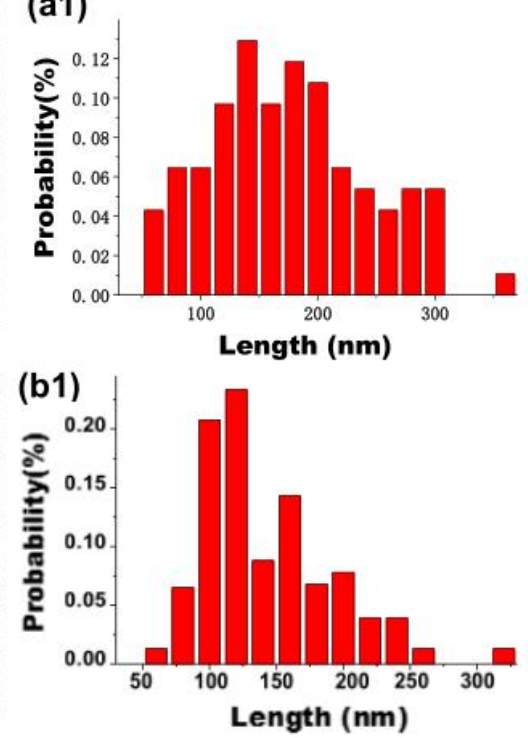

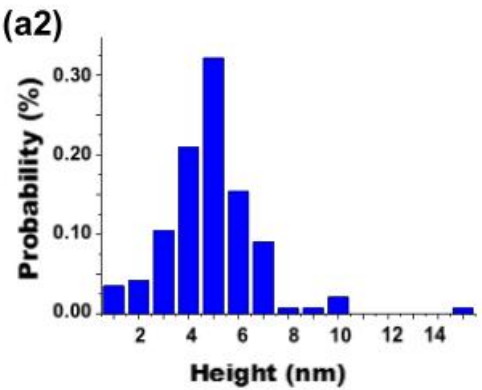

(b2) $0.30-$

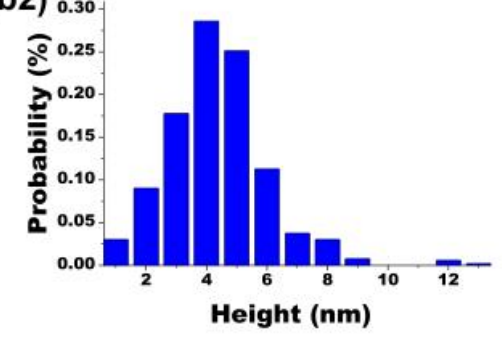

Fig. 6. TEM image and longitudinal and lateral size distribution of CNC prepared under different hydrolysis conditions (where $a$ is P60T70t4 and b is P60T70t7, whereas a1, a2, b1, and b2 are the length and height of the CNC, respectively.) 
The size and statistics of 120 sets of nanocellulose were measured here, and the size of CNC was roughly estimated. In the histograms a1 and a2 (Fig. 6), the average length and average diameter of the statistical CNC of P60T70t4 were $175.48 \mathrm{~nm}$ (range from 60 $\mathrm{nm}$ to $300 \mathrm{~nm}$ ) and $4.87 \mathrm{~nm}$ (range was $5 \pm 4 \mathrm{~nm}$ ), respectively, and the corresponding average aspect ratio was 36.03 (range was $38 \pm 12$ ). In the histograms b1 and b2, the average length and average diameter of the statistical CNC of P60T70t7 were $143.2 \mathrm{~nm}$ (range from $60 \mathrm{~nm}$ to $200 \mathrm{~nm}$ ) and $4.48 \mathrm{~nm}$ (range was $4.5 \pm 3.5 \mathrm{~nm}$ ), respectively, and the corresponding average aspect ratio was 31.96 (range was $30 \pm 11$ ). The harsher hydrolysis produced a shorter length of CNC, as previously noted (Elazzouzi-Hafraoui et al. 2008; Martínez-Sanz and Lagaron 2011). Due to its small diameter and large aspect ratio, CNC particles have been used in polymer nanocomposites to provide better mechanical properties (Grunert and Winter 2000; Orts et al. 2005; Santos et al. 2016; Nadir and Stephen 2017). And CNC particles having a large aspect ratio, when used as a nano-filler, have shown superior enhancement of properties (Mounika and Ravindra 2015).

\section{X-ray Diffraction (XRD)}

Crystallinity is a major factor affecting the mechanical properties of materials. The crystallinity of the $\mathrm{CNC}$ can be varied by controlling the temperature, time, and concentration of the hydrolysis. The X-ray diffraction patterns of the CNC obtained under different conditions are shown in Fig. 7. Strong diffraction peaks appeared at $14.8^{\circ}, 16.3^{\circ}$, and $22.5^{\circ}$, respectively, and weak diffraction peaks appeared at $34.3^{\circ}$, corresponding to four crystal faces of 1 $\overline{\mathrm{I}} 0,110,002$ and 040, respectively (Yu et al. 2013; Theivasanthi et al. 2018; Xing et al. 2018). The four crystal faces are characteristic peaks of typical natural cellulose, indicating that acid hydrolysis did not alter the cellulose form. However, the diffraction peak of the $\mathrm{CNC}$ controller deviated from the diffraction peak of the original cellulose. The Bragg angle of the $\mathrm{CNC}$ controller was slightly smaller than the Bragg angle of the material. According to the Bragg formula, $2 d \sin \theta=n \lambda$, the surface distance $d$ of the crystal unit of the CNC was increased. This phenomenon can be attributed to the change in the size of the cellulose, resulting in different long-range compressive forces of the crystal and the unit cell (French 2014; Coelho et al. 2018).

Generally, the larger the full width at half maximum of the diffraction peak is, the smaller the size of the cellulose is (Yu et al. 2013; Xing et al. 2018). At $2 \theta=22.4^{\circ}$, the full width at half maximum of the crystal diffraction peaks of P60T70t4, P70T70t4, and P60T70t7 increased sequentially, indicating that the size of the CNC decreased relatively with increasing concentration and/or reaction time, further confirming the results of DLS. In the X-ray diffraction pattern, the extreme values around $22^{\circ}$ and $18^{\circ}$ represented the crystalline and amorphous regions in the cellulose, respectively (French 2014; Xing et al. 2018). The peak changes at these two points can show changes in the crystal and amorphous regions of the CNC. At the peak of $18^{\circ}$, the crystal peaks of P60T70t4, P70T70t4, and P60T70t7 were weaker than the raw materials, indicating that p-TsOH can act on the amorphous region, and the amorphous region content of cellulose is decreased. At 22. $4^{\circ}$, the crystal peak intensities of P60T70t4, P70T70t4, and P60T70t7 first increased and then decreased, indicating that the relative content of the crystallization zone decreased with vigorous hydrolysis. According to Siegel's empirical method, the crystallinity of the raw materials and the CNC obtained under the conditions of P60T70t4, P70T70t4, and P60T70t7 were $78.9 \%, 89.9 \%, 90.1 \%$, and $82.6 \%$, respectively. The change in crystallinity indicated that $\mathrm{p}-\mathrm{TsOH}$ preferentially acted on the amorphous region under mild reaction conditions, retaining the crystalline region, and obtaining high crystallinity CNC. 
However, as the reaction time, acid concentration, and temperature were increased, acid hydrolysis became intense, attacking the crystalline zone, destroying hydrogen bonds, and producing more disordered domains in the cellulose, resulting in a decrease in crystallinity. The change in crystallinity is consistent with the literature (Chen et al. 2015; Xing et al. 2018).

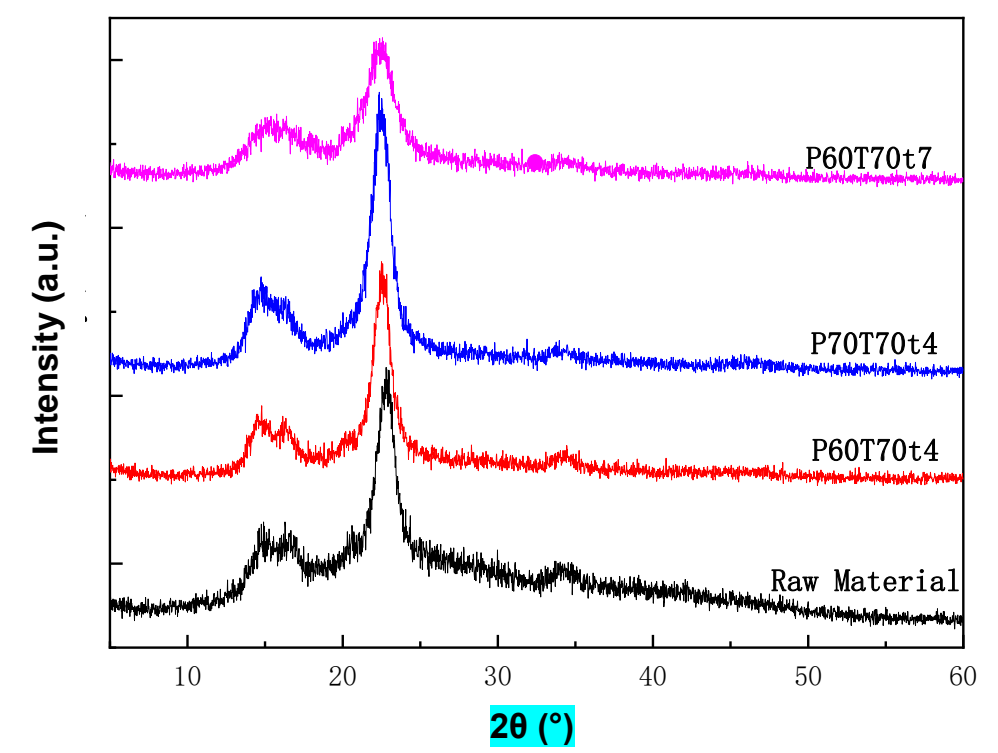

Fig. 7. X-ray diffraction pattern of CNC prepared under different hydrolysis treatments

\section{FTIR Analysis}

The infrared spectra of the softwood pulp board and CNC are shown in Fig. 8. The infrared spectrum of the CNC prepared by hydrolysis did not show new peaks, indicating that the $\mathrm{p}-\mathrm{TsOH}$ hydrolysis did not produce any new functional groups. The wavelengths of several samples mainly appeared in the ranges of 3700 to $2600 \mathrm{~cm}^{-1}$ and 800 to 1700 $\mathrm{cm}^{-1}$. The bands at $3400 \mathrm{~cm}^{-1}, 2900 \mathrm{~cm}^{-1}, 1430 \mathrm{~cm}^{-1}$, and $896 \mathrm{~cm}^{-1}$ were the characteristic absorption bands of CNC. This indicated that the internal structure of the CNC did not change during the preparation process. The bands at $3400 \mathrm{~cm}^{-1}$ can be attributed to the free $\mathrm{O}-\mathrm{H}$ stretching vibration of the $\mathrm{OH}$ group in the cellulose molecule, and the bands at 2900 $\mathrm{cm}^{-1}$ and $1430 \mathrm{~cm}^{-1}$ can be attributed to the $\mathrm{C}-\mathrm{H}$ stretching and bending of the $\mathrm{CH}_{2}$ group. The band at $1640 \mathrm{~cm}^{-1}$ was attributable to the bending vibration of the $\mathrm{OH}$ group of cellulose, which the presence of this band demonstrates that the cellulose contains adsorbed water (Yang et al. 2017; Coelho et al. 2018; Xing et al. 2018). The peak at $1430 \mathrm{~cm}^{-1}$ was attributed to the shear vibration of the hydrogen bond between the $\mathrm{C}-\mathrm{H}$ molecules in the dehydrated glucopyranose group (Leszczyńska et al. 2018). And the peak at $896 \mathrm{~cm}^{-1}$ can be attributed to the $\beta$-1,4-glycosidic linkage of the glucose unit in the cellulose (Mandal and Chakrabarty 2011; Thomas et al. 2015). As shown in Fig. 8, the peak vibration intensity at $896 \mathrm{~cm}^{-1}$ was weakened, indicating that the $\beta$-glycosidic bond was broken during the hydrolysis, and the size of cellulose was decreased. In the FTIR spectrum, the $1430 \mathrm{~cm}^{-1}$ and $896 \mathrm{~cm}^{-1}$ bands were considered to be crystalline bands and amorphous bands in cellulose, respectively (Adsul et al. 2012; Yang et al. 2017; Coelho et al. 2018). The crystallinity of cellulose can be estimated from the two peak intensities. The crystallinity of cellulose can be calculated not only by XRD, but also by the following formula (Ciolacu et al. 2011; Adsul et al. 2012), 


$$
\begin{aligned}
& C r R=A_{1430} / A_{896} \\
& A=-\log T
\end{aligned}
$$

where $A_{1430}$ represents the absorbance at $1430 \mathrm{~cm}^{-1}, A_{896}$ represents the absorbance at 896 $\mathrm{cm}^{-1}$, and $T$ represents the transmittance.

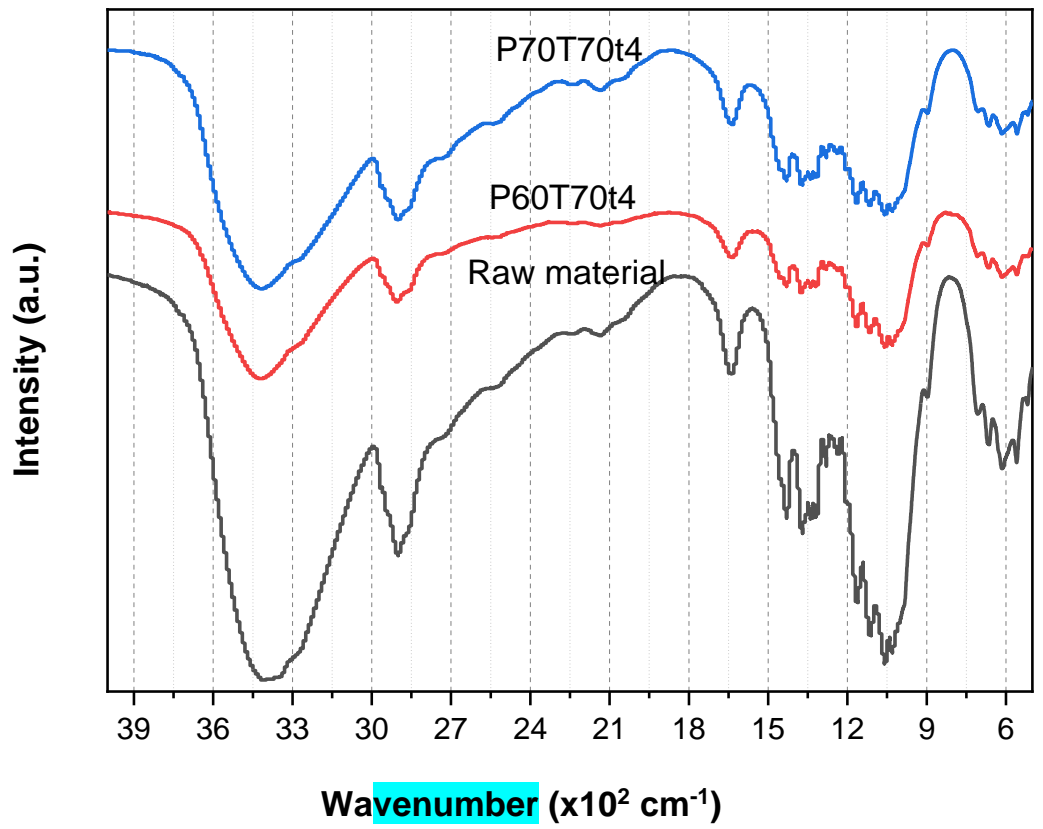

Fig. 8. Infrared spectra of CNC prepared under different hydrolysis conditions

The crystallinity of the raw materials and CNC was calculated to be $95.6 \%, 97.9 \%$, and $98.8 \%$, respectively (Various detection methods were used to calculate the difference in crystallinity, so there was a difference between infrared crystallinity and XRD crystallinity and value.). The trend is consistent with XRD and the XRD results are validated on the trend.

Table 2. Peak Intensity of CNC at $1430 \mathrm{~cm}^{-1}$ and $896 \mathrm{~cm}^{-1}$ under Different Conditions

\begin{tabular}{|c|c|c|c|}
\hline & Raw Material & P60T70t4 & P70T70t4 \\
\hline Transmittance at $1430 \mathrm{~cm}^{-1}(\%)$ & 71.0 & 84.8 & 91.30 \\
\hline Transmittance at $896 \mathrm{~cm}^{-1}(\%)$ & 86.4 & 93.2 & 96.5 \\
\hline
\end{tabular}

In natural cellulose, the hydrogen bond strengths of the two forms of cellulose I $\beta$ and $\mathrm{I} \alpha$ are different, and the position of the $\mathrm{O}-\mathrm{H}$ band in the infrared spectrum is also different, of which $750 \mathrm{~cm}^{-1}$ is attributed to cellulose $\mathrm{I} \alpha$ and $710 \mathrm{~cm}^{-1}$ is attributed to cellulose I $\beta$ (Åkerholm et al. 2004; Fahma et al. 2011; Yu et al. 2013). As shown in Fig. 6 , the I $\beta$ crystal form characteristic peak appeared in the raw material and the CNC: the $\mathrm{OH}$ out-of-plane bending at $710 \mathrm{~cm}^{-1}$ (Lu et al. 2010, 2013). After acid hydrolysis, it was observed that the peak vibration in the range $1200 \mathrm{~cm}^{-1}$ to $1000 \mathrm{~cm}^{-1}$ was obviously weakened, among which $1032 \mathrm{~cm}^{-1}$ and $1058 \mathrm{~cm}^{-1}$ belonged to the $\mathrm{C}-\mathrm{O}-\mathrm{C}$ stretching vibration in the sugar ring (Coelho et al. 2018), and $1113 \mathrm{~cm}^{-1}$ belonged to the glucose 
skeleton vibration. No new functional groups appeared in the spectrogram. It was speculated that during the hydrolysis reaction, the cellulose chain was opened, but no new groups were added. The role of the acid here was only to catalyze the hydrolysis. The peaks at $613 \mathrm{~cm}^{-1}$ and $669 \mathrm{~cm}^{-1}$ are attributed to the $\mathrm{O}-\mathrm{H}$ out-of-plane bending vibration, indicating that intermolecular hydrogen bonds interact with each other, resulting in aggregation of CNC (Yu et al. 2013), as shown in Figs. 5 and 6.

\section{X-ray Photoelectron Spectroscopy}

The surface properties of cellulose have an important influence on the final properties of the processing and utilization of cellulosic materials (Mitchell et al. 2005). XPS has become a new characterization tool for $\mathrm{CNC}$, which was used to analyze the change of cellulose carbon to oxygen ratio and to enable further speculation regarding the possible changes of cellulose groups during degradation. The XPS spectra of the raw materials and the CNC prepared under different conditions are shown in Fig. 9. The two peaks appearing in the XPS spectrum were attributed to the $\mathrm{C}$ and $\mathrm{O}$ elements in cellulose, and no sulfur was detected. According to the literature, no esterification occurred on the surface of CNC prepared by hydrolysis of $\mathrm{p}-\mathrm{TsOH}$ (Chen et al. 2016). Combined with the infrared spectrum, no ester peak appeared, from which it can be inferred that the surface of the CNC was not connected to the sulfonate group. Therefore, the stability of the suspension of $\mathrm{CNC}$ was relatively inferior compared to the introduction of sulfate groups by the sulfuric acid process. The $\mathrm{O} / \mathrm{C}$ ratio of the cellulose surface was an important indicator of cellulose oxidation ( $\mathrm{Li}$ et al. 2014). As shown in Table 3, the $\mathrm{O} / \mathrm{C}$ ratio of the $\mathrm{CNC}$ was increased by $0.2 \%$ after the hydrolysis, which can consider that the cellulose did not oxidize during the hydrolysis.
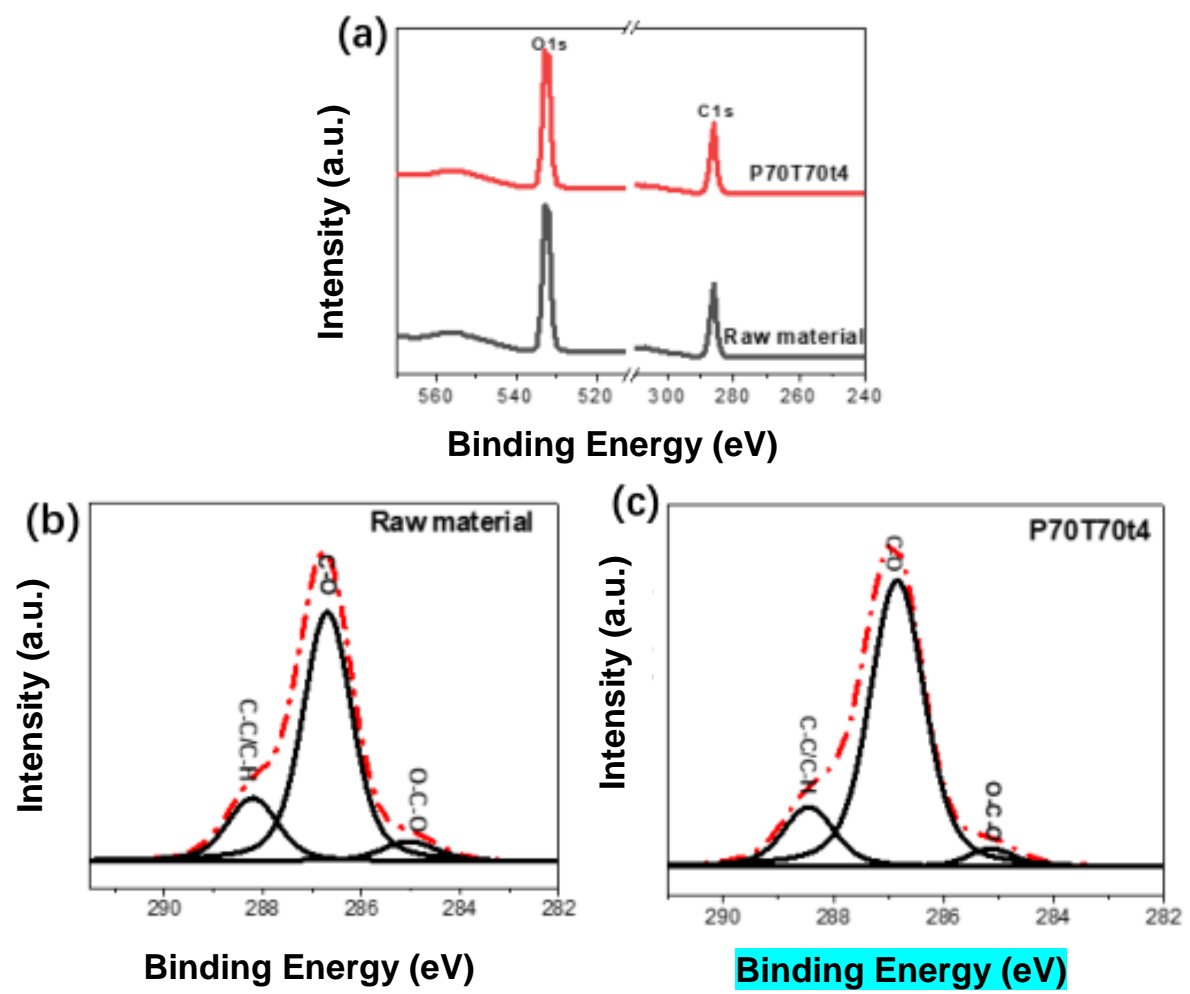

Fig. 9. X-ray energy spectrum of raw materials and CNC prepared under different conditions 
Table 3. O/C Ratio of Raw Materials and CNC of P70T70t4

\begin{tabular}{|c|c|c|c|c|}
\hline \multirow{2}{*}{} & \multirow{2}{*}{ O/C Ratio } & \multicolumn{3}{|c|}{ Binding Energy } \\
\cline { 3 - 5 } & & $285.0 \mathrm{eV}(\mathrm{C}-\mathrm{C} / \mathrm{C}-\mathrm{H})$ & $286.6 \mathrm{eV}(\mathrm{C}-\mathrm{O})$ & $288.1 \mathrm{ev}(\mathrm{O}-\mathrm{C}-\mathrm{O})$ \\
\hline Raw material & 0.812 & 0.19 & 0.74 & 0.066 \\
\hline P70T70t4 & 0.814 & 0.15 & 0.80 & 0.05 \\
\hline
\end{tabular}

The binding energy spectra of the $\mathrm{C} 1 \mathrm{~s}$ of the raw materials and the $\mathrm{CNC}$ were deconvolved into three Gaussian spectra. The peak positions of these curves were fixed at $285.0 \mathrm{eV}, 286.6 \mathrm{eV}$, and $288.1 \mathrm{eV}$, representing C-C/C-H, C-O, and O-C-O, respectively (Johansson et al. 2005; Mitchell et al. 2005; Topalovic et al. 2007). Theoretically, the XPS spectrum of cellulose exhibits $\mathrm{C} 1 \mathrm{~s}$ peaks only at a binding energy of $286.6 \mathrm{eV}$ (C-O) alcohol or ether) and $288.1 \mathrm{eV}(\mathrm{O}-\mathrm{C}-\mathrm{O}$, diether or carbonyl) with a relative intensity ratio of 5:1, and the $\mathrm{C} 1 \mathrm{~s}$ expressed at $285.0 \mathrm{eV}(\mathrm{C}-\mathrm{C} / \mathrm{C}-\mathrm{H}$, aliphatic) binding energy are not characteristic of cellulose; rather, they may be derived from lignin, fatty acids, or waxes. (Sapieha et al. 1990; Belgacem et al. 1995; Mitchell et al. 2005; Gray et al. 2010). According to Table 3, the value of $\mathrm{O} / \mathrm{C}$ ratio was lower than the theoretical value of pure cellulose 0.83 (Gray et al. 2010). The ratio of C1s at the binding energy of $285 \mathrm{eV}$ decreased from $19 \%$ to $15 \%$ after hydrolysis, indicating that the non-cellulosic material on the cellulose surface was removed with hydrolysis ( $\mathrm{p}-\mathrm{TsOH}$ can remove lignin efficiently) (Bian et al. 2017; Chen et al. 2017). The proportion of C1s at the binding energy of 286.6 $\mathrm{eV}$ increased, possibly due to acid hydrolysis opening the amorphous region, exposing more alcoholic hydroxyl groups.

\section{Thermogravimetric Analysis}

Results of the thermogravimetric (TG) and derived thermogravimetry (DTG) of CNC obtained under different preparation conditions are shown in Fig. 10 and Table 4. In general, cellulose pyrolysis is divided into two stages, which the first stage is the evaporation of water, the dehydration of cellulose into dehydrogenated cellulose, and the second stage may be related to cellulose depolymerization (Wang et al. 2007; Morán et al. 2008; Yildirim and Shaler 2017).
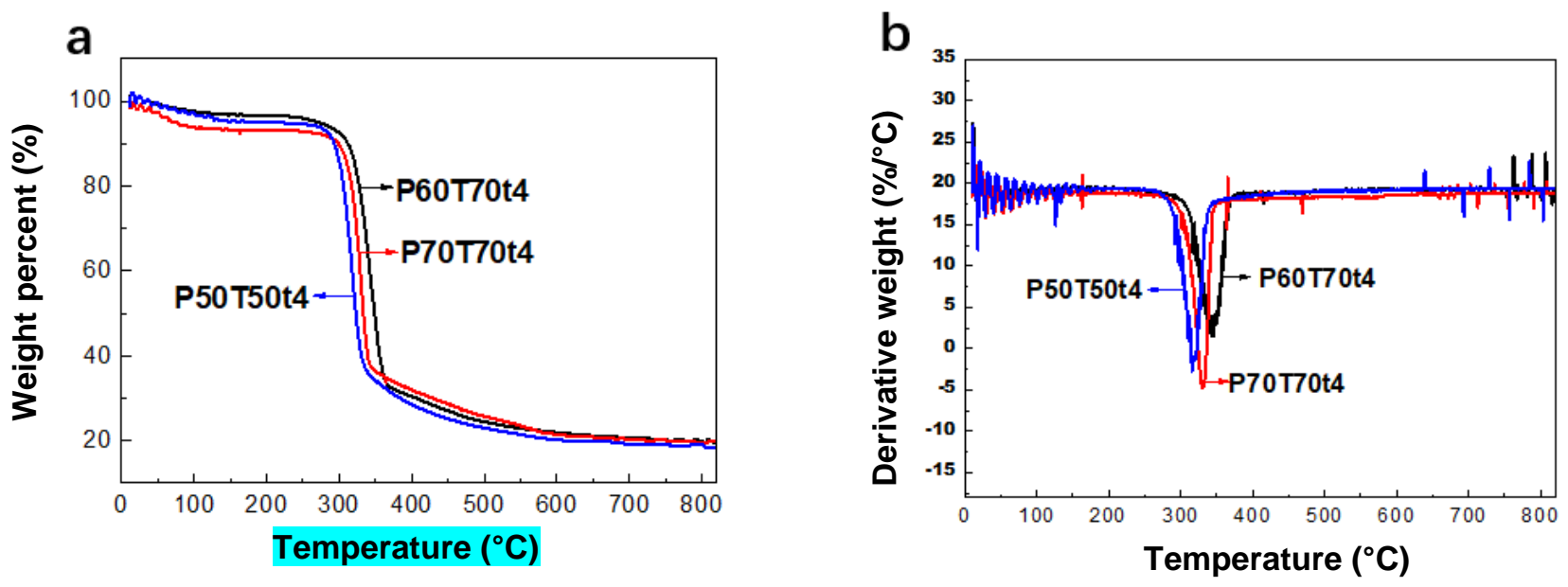

Fig. 10. TG and DTG curves of CNC obtained under the treatment of P50T50t4, P60T70t4, and P70T70t4 
As shown in the TG curve (Fig. 10a), the free water of the cellulose evaporated near $100{ }^{\circ} \mathrm{C}$, resulting in a small weight loss (about $2.5 \%$ ) of the CNC. Subsequently, the weight of the $\mathrm{CNC}$ began to decrease obviously at about $300{ }^{\circ} \mathrm{C}$, wherein the initial thermal degradation temperature of P50T50t4 was $294{ }^{\circ} \mathrm{C}$, the initial thermal degradation temperature of the $\mathrm{CNC}$ of P60T70t4 was $310{ }^{\circ} \mathrm{C}$, and the initial thermal degradation temperature of P70T70t 4 was $303{ }^{\circ} \mathrm{C}$. The change in temperature rate here was due to the organic matter starting to decompose at this temperature, and the weight loss was about $60 \%$ from $300{ }^{\circ} \mathrm{C}$ to $370{ }^{\circ} \mathrm{C}$. Finally, the weight loss of cellulose was slow after about 370 ${ }^{\circ} \mathrm{C}$, and the carbon residue of P50T50t4, P60T70t4, and P70T70t4 was about $18.9 \%$, $19.8 \%, 19.5 \%$, respectively, when the temperature reached $800{ }^{\circ} \mathrm{C}$. The increase in carbon residue for the $\mathrm{CNC}$ of $70{ }^{\circ} \mathrm{C}$ samples in comparison with $\mathrm{CNC}$ of $50{ }^{\circ} \mathrm{C}$ may be due to small size and increased number of free end chains ( $\mathrm{Li}$ et al. 2012). The DTG curve described the rate of cellulose pyrolysis. The CNC of P50T50t4, P60T70t4, and P70T70t4 reached maximum values at $317^{\circ} \mathrm{C}, 350{ }^{\circ} \mathrm{C}$, and $331^{\circ} \mathrm{C}$, respectively. Combined with the TG and DTG curves in Fig. 10(a)(b), it was not difficult to find that the CNC obtained by the P60T70t4 condition had the best thermal stability. According to the literature data, the degradation temperature of the CNC obtained by the sulfuric acid method was about 200 ${ }^{\circ} \mathrm{C}$ (Shafizadeh et al. 1976; Roman and Winter 2004). Therefore, the thermal stability of $\mathrm{CNC}$ obtained by hydrolysis of $\mathrm{p}-\mathrm{TsOH}$ acid was generally better than that of sulfuric acid method. The reason for this phenomenon may be that the surface of the CNC obtained by the hydrolysis by sulfuric acid introduced sulfate groups, resulting in more heat exposure (Kim et al. 2001; Long et al. 2017; Nadir and Stephen 2017), while the CNC obtained by hydrolysis of $\mathrm{p}-\mathrm{TsOH}$ did not introduce new groups on the surface. According to the literature, the introduction of sulfate was the main reason for the low thermal stability (Roman et al. 2004).

Table 4. Weight Loss and Degradation Temperature of CNC under Different Hydrolysis

\begin{tabular}{|l|c|c|c|c|c|c|}
\hline & $T_{\mathrm{a}}\left({ }^{\circ} \mathrm{C}\right)$ & $\begin{array}{c}\text { Residue at } T_{\mathrm{a}} \\
(\%)\end{array}$ & $T_{\mathrm{b}}\left({ }^{\circ} \mathrm{C}\right)$ & $\begin{array}{c}\text { Residue at } T_{\mathrm{b}} \\
(\%)\end{array}$ & $T_{\max }\left({ }^{\circ} \mathrm{C}\right)$ & $\begin{array}{c}\text { Residue } \\
\text { at } 800{ }^{\circ} \mathrm{C} \\
(\%)\end{array}$ \\
\hline P50T50t4 & 112 & 97.2 & 294 & 91.0 & 317 & 18.7 \\
\hline P60T70t4 & 112 & 93.6 & 310 & 90.1 & 350 & 19.8 \\
\hline P70T70t4 & 112 & 96.4 & 303 & 92.2 & 331 & 19.6 \\
\hline
\end{tabular}

Note: $T_{\mathrm{b}}$ represents the start of degradation temperature; $T_{\max }$ represents the maximum degradation rate.

\section{CONCLUSIONS}

1. The cellulose nanocrystals (CNC) with excellent properties were successfully prepared by hydrolysis of p-toluene sulfonic acid (p-TsOH). It was shown that p-TsOH hydrolysis is a green and highly efficient preparation method, and $\mathrm{p}-\mathrm{TsOH}$ can be recovered by crystallization, and the recovery rate can reach $71.8 \%$. 
2. The CNC were characterized by SEM, TEM, XRD, FTIR, XPS, and TGA. The results showed that the crystallinity index of the CNC with a high aspect ratio (about 33) reached $90 \%$. During the hydrolysis process, no esterification reaction occurred on the surface of the cellulose, and no new groups were introduced on the surface. Therefore, the thermal stability of the CNC was good, and the degradation temperature was about $310{ }^{\circ} \mathrm{C}$. During the hydrolysis process, the crystal form and internal structure of the cellulose were not destroyed.

3. The $\mathrm{CNC}$ prepared by hydrolysis of $\mathrm{p}-\mathrm{TsOH}$ does not introduce new functional groups, and the CNC still has the crystal form and composition of natural cellulose. Therefore, $\mathrm{CNC}$ can be used in the fields of electronic components, composite materials, reinforcement materials, and medical materials.

\section{ACKNOWLEDGMENTS}

This research was supported by the Foundation of Key Laboratory of Pulp and Paper Science and Technology of the Ministry of Education (No. KF201706), and by the Shandong Province of China Key Research and Development Project (No. 2019GGX102026) and Shandong Province major innovation project (2018CXGC1001). One of the authors expresses their deepest gratitude to Dr. Songlin Wang who provided valuable guidance during the course of conducting and reporting of this work.

\section{REFERENCES CITED}

Adsul, M., Soni, S. K., Bhargava, S. K., and Bansal, V. (2012). "Facile approach for the dispersion of regenerated cellulose in aqueous system in the form of nanoparticles," Biomacromolecules 13(9), 2890-2895. DOI: 10.1021/bm3009022

Åkerholm, M., Hinterstoisser, B., and Salmén, L. (2004). "Characterization of the crystalline structure of cellulose using static and dynamic FT-IR spectroscopy," Carbohydrate Research 339(3), 569-578. DOI: 10.1016/j.carres.2003.11.012

Aulin, C., Netrval, J., Wågberg, L., and Lindström, T. (2010). "Aerogels from nanofibrillated cellulose with tunable oleophobicity," Soft Matter 6(14), 3298-3305. DOI: $10.1039 / \mathrm{c} 001939 \mathrm{a}$

Belbekhouche, S., Bras, J., Siqueira, G., Chappey, C., Lebrun L., Khelifi B., Marais S., and Dufresne A. (2011). "Water sorption behavior and gas barrier properties of cellulose whiskers and microfibrils films," Carbohydrate Polymers 83(4), 1740-1748. DOI: 10.1016/j.carbpol.2010.10.036

Belgacem, M. N., Czeremuszkin, G., Sapieha, S., and Gandini, A. (1995). "Surface characterization of cellulose fibres by XPS and inverse gas chromatography," Cellulose 2(3), 145-157. DOI: 10.1007/BF00813015

Bian, H., Chen, L., Dai, H., and Zhu, J. Y. (2017a). "Integrated production of lignin containing cellulose nanocrystals (LCNC) and nanofibrils (LCNF) using an easily recyclable di-carboxylic acid," Carbohydrate Polymers 167, 167-176. DOI: 10.1016/j.carbpol.2017.03.050

Bian, H., Chen, L., Gleisner, R., Dai, H., and Zhu, J. Y. (2017b). "Producing wood-based nanomaterials by rapid fractionation of wood at $80{ }^{\circ} \mathrm{C}$ using a recyclable acid 
hydrotrope," Green Chemistry 19(14), 3370-3379. DOI: 10.1039/C7GC00669A

Brinchi, L., Cotana, F., Fortunati, E., and Kenny, J. M. (2013). "Production of nanocrystalline cellulose from lignocellulosic biomass: Technology and applications," Carbohydrate Polymers 94(1), 154-169. DOI: 10.1016/j.carbpo1.2013 .01 .033

Carlsson, D. O., Nystršm, G., Ferraz, N., Nyholm, L., Mihranyan, A., and Strømme, M. (2012). "[P1.028] Development of nanocellulose/polypyrrole composites towards blood purification," Procedia Engineering 44, 733-736. DOI:

10.1016/j.proeng.2012.08.550

Chang, P. R., Jian, R., Zheng, P., and Yu, J. G. (2010). "Preparation and properties of glycerol plasticized-starch (GPS)/cellulose nanoparticle $(\mathrm{CN})$ composites," Carbohydrate Polymers 79(2), 301-305. DOI: 10.1016/j.carbpol.2009.08.007

Chen, L., Dou, J., Ma, Q., Li, N., Wu, R., Bian, H., Yelle, D., Vuorinen, T., Fu, S., Pan, X., and Zhu, J. Y. (2017). "Rapid and near-complete dissolution of wood lignin at $\leq$ $80^{\circ} \mathrm{C}$ by a recyclable acid hydrotrope," Science Advances 3(9), e1701735. DOI: 10.1126/sciadv.1701735

Chen, L., Wang, Q., Hirth, K., Baez, C., Agarwal, U. P., and Zhu, J. Y. (2015). "Tailoring the yield and characteristics of wood cellulose nanocrystals (CNC) using concentrated acid hydrolysis," Cellulose 22(3), 1753-1762. DOI: 10.1007/s10570015-0615-1

Chen, L., Zhu, J. Y., Baez, C., Kitin, P., and Elder, T. (2016). "Highly thermal-stable and functional cellulose nanocrystals and nanofibrils produced using fully recyclable organic acids," Green Chem. 18(13), 3835. DOI: 10.1039/c6gc00687f

Choi, Y. J., and Simonsen, J. (2006). "Cellulose nanocrystal-filled carboxymethyl cellulose nanocomposites," Journal of Nanoscience and Nanotechnology 6(3), 633639. DOI: 10.1166/jnn.2006.132

Ciolacu, D., Ciolacu, F., and Popa, V. I. (2011). "Amorphous cellulose - Structure and characterization," Cellulose Chemistry and Technology 45(1), 13-21. DOI: 10.2488/jwrs.57.42

Coelho, D. C. B. K. C., Voorwald, H. J. C., Cioffi, Maria Odila Hilário, Rezende, M. C., and Arantes, V. (2018). "Preparation of nanocellulose from Imperata brasiliensis grass using Taguchi method," Carbohydrate Polymers 192, 337-346. DOI: 10.1016/j.carbpol.2018.03.055

Dong, H., Snyder, J. F., Tran, D. T., and Leadore, J. L. (2013). "Hydrogel, aerogel, and film of cellulose nanofibrils functionalized with silver nanoparticles," Carbohydrate Polymers 95(2), 760-767. DOI: 10.1016/j.carbpol.2013.03.041

Dufresne, A. (2013). "Nanocellulose: A new ageless bionanomaterial," Materials Today 16(6), 220-227. DOI: 10.1016/j.mattod.2013.06.004

Elazzouzi-Hafraoui, S., Nishiyama, Y., Putaux, J. L., Heux, L., Dubreuil, F., and Rochas, C. (2008). "The shape and size distribution of crystalline nanoparticles prepared by acid hydrolysis of native cellulose," Biomacromolecules 9(1), 57-65. DOI: $10.1021 / \mathrm{bm} 700769 \mathrm{p}$

Fahma, F., Iwamoto, S., Hori, N., Iwata, T., and Takemura, A. (2011). "Effect of preacid-hydrolysis treatment on morphology and properties of cellulose nanowhiskers from coconut husk," Cellulose 18(2), 443-450. DOI: 10.1007/s10570-010-9480-0

Fernandes, E. M., Pires, R. A., João F. Mano, and Reis, R. L. (2013).

"Bionanocomposites from lignocellulosic resources: properties, applications and future trends for their use in the biomedical field," Progress in Polymer Science 
38(10-11), 1415-1441. DOI: 10.1016/j.progpolymsci.2013.05.013

French, A. D. (2014). "Idealized powder diffraction patterns for cellulose polymorphs," Cellulose 21(2), 885-896. DOI: 10.1007/s10570-013-0030-4

Gray, D. G., Weller, M., Ulkem, N., and Lejeune, A. (2010). "Composition of lignocellulosic surfaces: Comments on the interpretation of XPS spectra," Cellulose 17(1), 117-124. DOI: 10.1007/s10570-009-9359-0

Guo, X., Liu, L., Hu, Y., and Wu, Y. (2018). "Water vapor sorption properties of tempo oxidized and sulfuric acid treated cellulose nanocrystal films," Carbohydrate Polymers 197, 524-530. DOI: 10.1016/j.carbpol.2018.06.0-27

Habibi, Y., Lucia, L. A., and Rojas, O. J. (2010). "Cellulose nanocrystals: Chemistry, self-assembly, and applications," Chemical Reviews 110(6), 3479-3500. DOI: $10.1021 / \mathrm{cr} 900339 \mathrm{w}$

Heggset, E. B., Chinga-Carrasco, G., and Syverud, K. (2017). "Temperature stability of nanocellulose dispersions," Carbohydrate Polymers 157, 114-121. DOI: 10.1016/j.carbpol.2016.09.077

Herrera, M. A., Mathew, A. P., and Oksman, K. (2014). "Gas permeability and selectivity of cellulose nanocrystals films (layers) deposited by spin coating," Carbohydrate Polymers 112, 494-501. DOI: 10.1016/j.carbpol.2014.06.036

Johansson, L. S., Campbell, J. M., Fardim, P., Heijnesson Hultén, A., Boisvert, J. P., and Ernstsson, M. (2005). "An XPS round robin investigation on analysis of wood pulp fibres and filter paper," Surface Science 584(1), 126-132. DOI: 10.1016/j.susc.2005.01.062

Karim, Z., Claudpierre, S., Grahn, M., Oksman, K., and Mathew, A. (2016). "Nanocellulose based functional membranes for water cleaning: tailoring of mechanical properties, porosity and metal ion capture," Journal of Membrane Science 514, 418-428. DOI: 10.1016/j.memsci.2016.05.018

Kim, D. Y., Nishiyama, Y., Wada, M., and Kuga, S. (2001). "High-yield carbonization of cellulose by sulfuric acid impregnation," Cellulose 8(1), 29-33. DOI:

10.1023/a:1016621103245

Leszczyńska, Agnieszka, Radzik, P., Haraźna, K., and Pielichowski, K. (2018). “Thermal stability of cellulose nanocrystals prepared by succinic anhydride assisted hydrolysis," Thermochimica Acta 663, 145-156. DOI: 10.1016/j.tca.2018.03.015

Li, W., Yue, J., and Liu, S. (2012). "Preparation of nanocrystalline cellulose via ultrasound and its reinforcement capability for poly(vinyl alcohol) composites," Ultrasonics Sonochemistry 19(3), 479-485. DOI: 10.1016/j.ultsonch.2011.11.007

Li, J., Wang, Y., Wei, X., Wang, F., Han, D., Wang, Q., and Kong, L. (2014). "Homogeneous isolation of nanocelluloses by controlling the shearing force and pressure in microenvironment," Carbohydrate Polymers 113, 388-393. DOI: 10.1016/j.carbpol.2014.06.085

Lima, M. M. D. S., and Borsali, R. (2004). "Rodlike cellulose microcrystals: structure, properties, and applications," Macromolecular Rapid Communications 25(7), 771787. DOI: $10.1002 /$ marc. 200300268

Lin, N., and Dufresne, A. (2014). "Nanocellulose in biomedicine: Current status and future prospect," European Polymer Journal 59, 302-325. DOI: 10.1016/j.eurpolymj.2014.07.025

Liu, C., Li, B., Du, H., Lv, D., Zhang, Y., Yu, G., Mu, X., and Peng, H. (2016). "Properties of nanocellulose isolated from corncob residue using sulfuric acid, formic acid, oxidative and mechanical methods," Carbohydrate Polymers 151, 716-724. 
DOI: 10.1016/j.carbpol.2016.06.025

Liu, P., Borrell, P. F., Božič, M., Kokol, V., Oksman, K., and Mathew, A. P. (2015). "Nanocelluloses and their phosphorylated derivatives for selective adsorption of $\mathrm{Ag}^{+}$, $\mathrm{Cu}^{2+}$, and $\mathrm{Fe}^{3+}$ from industrial effluents," Journal of Hazardous Materials 294, 177185. DOI: $10.1016 /$ j.jhazmat.2015.04.001

Łojewska, J., Missori, M., Lubańska, A., Grimaldi, P., Zięba, K., Proniewicz, L. M., and Congiu Castellano, A. (2007). "Carbonyl groups development on degraded cellulose. correlation between spectroscopic and chemical results," Applied Physics A 89(4), 883-887. DOI: 10.1007/s00339-007-4220-5

Long, Y., Yu, Y., Chua, Y. W., and Wu, H. (2017). "Acid-catalysed cellulose pyrolysis at low temperatures," Fuel 193, 460-466. DOI: 10.1016/j.fuel.2016.12.067

Lu, P., and Hsieh, Y. L. (2010). "Preparation and properties of cellulose nanocrystals: rods, spheres, and network," Carbohydrate Polymers 82(2), 329-336. DOI: 10.1016/j.carbpol.2010.04.073

Lu, Z., Fan, L., Zheng, H., Lu, Q., Liao, Y., and Huang, B. (2013). "Preparation, characterization and optimization of nanocellulose whiskers by simultaneously ultrasonic wave and microwave assisted," Bioresour. Technol. 146(10), 82-88. DOI: 10.1016/j.biortech.2013.07.047

Maciel, M. M. Á. D., Benini, K. C. C. C., Voorwald, H. J. C., and Cioffi, M. O. H. (2019). "Obtainment and characterization of nanocellulose from an unwoven industrial textile cotton waste: Effect of acid hydrolysis conditions," International Journal of Biological Macromolecules 126(1). 496-506. DOI: 10.1016/j.ijbiomac.2018.12.202.

Mandal, A., and Chakrabarty, D. (2011). "Isolation of nanocellulose from waste sugarcane bagasse (scb) and its characterization," Carbohydrate Polymers 86(3), 1291-1299. DOI: 10.1016/j.carbpol.2011.06.030

Martínez-Sanz, M., Lopez-Rubio, A., and Lagaron, J. M. (2011). "Optimization of the nanofabrication by acid hydrolysis of bacterial cellulose nanowhiskers," Carbohydrate Polymers 85(1), 228-236. DOI: 10.1016/j.carbpol.2011.02.021

Miettunen, K., Vapaavuori, J., Tiihonen, A., Poskela, A., Lahtinen, P., Halme, J., and Lund, P. (2014). "Nanocellulose aerogel membranes for optimal electrolyte filling in dye solar cells," Nano. Energy 8, 95-102. DOI: 10.1016/j.nanoen.2014.05.013

Mirhosseini, H., Tan, C. P., Hamid, N. S. A., and Yusof, S. (2008). "Effect of arabic gum, xanthan gum and orange oil contents on $\zeta$-potential, conductivity, stability, size index and $\mathrm{pH}$ of orange beverage emulsion," Colloids \& Surfaces A Physicochemical \& Engineering Aspects 315(1-3), 47-56. DOI: 10.1016-/j.colsurfa.2007.07.007

Mishra, R. K., Sabu, A., and Tiwari, S. K. (2018). "Materials chemistry and the futurist eco-friendly applications of nanocellulose: status and prospect," Journal of Saudi Chemical Society 22(8), 949-978. DOI: 10.1016/j.jscs.2018.02.005

Mitchell, R., Carr, C. M., Parfitt, M., Vickerman, J. C., and Jones, C. (2005). "Surface chemical analysis of raw cotton fibres and associated materials," Cellulose 12(6), 629-639. DOI: 10.1007/s10570-005-9000-9

Morais, J. P. S., Rosa, M. D. F., de Souza Filho, Men de sá Moreira, Nascimento, L. D., Do Nascimento, D. M., and Cassales, A. R. (2013). "Extraction and characterization of nanocellulose structures from raw cotton linter," Carbohydrate Polymers 91(1), 229-235. DOI: 10.1016/j.carbpol.2012.08.010

Morán, J. I., Alvarez, V. A., Cyras, V. P., and Vázquez, A. (2008). "Extraction of cellulose and preparation of nanocellulose from sisal fibers," Cellulose 15(1), 149. 
DOI: $10.1007 / \mathrm{s} 10570-007-9145-9$

Mounika, M., and Ravindra, K. (2015). "Characterization of nanocomposites reinforced with cellulose whiskers: a review," Materials Today: Proceedings 2(4-5), 3610-3618. DOI: 10.1016/j.matpr.2015.07.107

Nadir, Y., and Stephen, S. (2017). "A study on thermal and nanomechanical performance of cellulose nanomaterials (CNs)," Materials 10(7), 718, DOI: 10.3390/ma10070718

Nair, S. S., Zhu, J. Y., Deng, Y., and Ragauskas, A. J. (2014). "High performance green barriers based on nanocellulose," Sustainable Chemical Processes 2(1), 23. DOI: 10.1186/s40508-014-0023-0

Oksman, K., Yvonne Aitomäki, Mathew, A. P., Siqueira, G., Zhou, Q., Butylina, S., Tanpichai, S., Zhou, X., and Hooshmand, S. (2016). "Review of the recent developments in cellulose nanocomposite processing," Composites Part A: Applied Science \& Manufacturing 83, 2-18. DOI: 10.1016/j.compositesa.2015.1-0.041

Orts, W. J., Shey, J., Imam, S. H., Glenn, G. M., Guttman, M. E., and Revol, J. F. (2005). "Application of cellulose microfibrils in polymer nanocomposites," Journal of Polymers and the Environment 13(4), 301-306. DOI: 10.1007/s10924-005-5514-3

Pereira, André Luís S., Nascimento, D. M. D., Souza Filho, Men de sá M., Morais, J. P. S., Vasconcelos, N. F., Feitosa, J. P. A., Brígida, Ana Iraidy S., Rosa, and Morsyleide de F. (2014). "Improvement of polyvinyl alcohol properties by adding nanocrystalline cellulose isolated from banana pseudostems," Carbohydrate Polymers 112, 165-172. DOI: 10.1016/j.carbpol.2014.05.090

Roman, M., and Winter, W. T. (2004). "Effect of sulfate groups from sulfuric acid hydrolysis on the thermal degradation behavior of bacterial cellulose," Biomacromolecules 5(5), 1671-1677. DOI: 10.1021/bm034519+

Samir, M. A., Alloin, F., and Dufresne, A. (2005). "Review of recent research into cellulosic whiskers, their properties and their application in nanocomposites field," Biomacromolecules 6(2), 612-626. DOI: 10.1021/bm0493685

Santos, F. A. D., Iulianelli, G. C. V., and Maria Inês Bruno Tavares. (2016). "The use of cellulose nanofillers in obtaining polymer nanocomposites: Properties, processing, and applications," Materials Sciences \& Applications 07(5):257-294. DOI: 10.4236/msa.2016.75026

Sapieha, S., Verreault, M., Klemberg-Sapieha, J. E., Sacher, E., and Wertheimer, M. R. (1990). "X-ray photoelectron study of the plasma fluorination of lignocellulose," Applied Surface Science 44(2), 165-169. DOI: 10.1016/0169-4332(90)90105-9

Seabra, A. B., Bernardes, J. S., Wagner J. Fávaro, Paula, A. J., and Nelson Durán. (2017). "Cellulose nanocrystals as carriers in medicine and their toxicities: a review," Carbohydrate Polymers 181, 514. DOI: 10.1016/j.carbpol.2017.12.014

Segal, L., Creely, J. J., Martin, A. E., and Conrad, C. M. (1959). "An empirical method for estimating the degree of crystallinity of native cellulose using the X-ray diffractometer," Text. Res. J. 29(10), 786-794. DOI: 10.1177/0040517559029-01003

Shafizadeh, F., Sarkanen, K. V., and Tillman, D. A. (1976). "Thermal uses and properties of carbohydrates and lignins," Thermal Uses \& Properties of Carbohydrates \& Lignins 99(10), 317-320. DOI: 10.1002/bjs.8876

Sol, V. (2016). "Development of curcumin-cyclodextrin/cellulose nanocrystals complexes: new anticancer drug delivery systems," Bioorganic \& Medicinal Chemistry Letters 26(3), 941-945. DOI: 10.1016/j.bmcl.2015.12.060

Stelte, W., and Sanadi, A. R. (2009). "Preparation and characterization of cellulose nanofibers from two commercial hardwood and softwood pulps," Industrial \& 
Engineering Chemistry Research 48(24), 11211-11219. DOI: 10.1021/ie9011672

Teixeira, R. S. S., Silva, Ayla Sant'Ana da, Jang, J. H., Kim, H. W., Ishikawa, K., Endo, T., Seung-HwanLee, and Elba P. S. Bon. (2015). "Combining biomass wet disk milling and endoglucanase/ $\beta$-glucosidase hydrolysis for the production of cellulose nanocrystals," Carbohydrate Polymers 128, 75-81. DOI:

10.1016/j.carbpol.2015.03.087

Theivasanthi, T., Anne, F. C., Toyin, A. J., Gopinath, S., and Ravichandran, R. (2018). "Synthesis and characterization of cotton fiber-based nanocellulose," International Journal of Biological Macromolecules 109. DOI: 10.1016/j.ijbio-mac.2017.11.054

Thomas, M. G., Abraham, E., Jyotishkumar, P., Pothan, L. A., Maria, H. J., and Thomas, S. (2015). "Nanocelluloses from jute fibres and their nanocomposites with natural rubber: preparation and characterization," International Journal of Biological Macromolecules 81, 768-777. DOI: 10.1016/j.ijbiomac.2015.08.053

Tian, C., Yi, J., Wu, Y., Wu, Q., Qing, Y., and Wang, L. (2016). "Preparation of highly charged cellulose nanofibrils using high-pressure homogenization coupled with strong acid hydrolysis pretreatments," Carbohydrate Polymers 136, 485-492. DOI: 10.1016/j.carbpol.2015.09.055

Tingaut, P., Zimmermann, T., and Sèbe, Gilles. (2012). "Cellulose nanocrystals and microfibrillated cellulose as building blocks for the design of hierarchical functional materials," Journal of Materials Chemistry 22(38), 20105. DOI: 10.1039/c2jm32956e

Topalovic, T., Nierstrasz, V. A., Bautista, L., Jocic, D., Navarro, A., and Warmoeskerken, M. M. C. G. (2007). "XPS and contact angle study of cotton surface oxidation by catalytic bleaching," Colloids and Surfaces A (Physicochemical and Engineering Aspects) 296(1-3), 76-85. DOI: 10.1016/j.colsurfa.2006.09.026

Wang, N., Ding, E., and Cheng, R. (2007). "Thermal degradation behaviors of spherical cellulose nanocrystals with sulfate groups," Polymer 48(12), 3486-3493. DOI: 10.1016/j.polymer.2007.03.062

Xing, J., Tao, P., Wu, Z., Xing, C., Liao, X., and Nie, S. (2018). "Nanocellulosegraphene composites: A promising nanomaterial for flexible supercapacitors," Carbohydrate Polymers 207, 447-459. DOI: 10.1016/j.carbpol.2018.12.010

Xing, L., Gu, J., Zhang, W., Tu, D., and Hu, C. (2018). "Cellulose I and II nanocrystals produced by sulfuric acid hydrolysis of Tetra-pak cellulose I," Carbohydrate Polymers 192, 184-192. DOI: 10.1016/j.carbpol.2018.03.042

Xu, X., Liu, F., Jiang, L., Zhu, J. Y., Haagenson, D., and Wiesenborn, D. P. (2013). "Cellulose nanocrystals vs. cellulose nanofibrils: A comparative study on their microstructures and effects as polymer reinforcing agents," ACS Applied Materials \& Interfaces 5(8), 2999-3009. DOI: 10.1021/am302624t

Yang, X., Han, F., Xu, C., Jiang, S., Huang, L., Liu, L., and Xia, Z. (2017). "Effects of preparation methods on the morphology and properties of nanocellulose (NC) extracted from corn husk," Industrial Crops and Products 109, 241-247. DOI: 10.1016/j.indcrop.2017.08.032

Yatagai, M., and Zeronian, S. H. (1994). "Effect of ultraviolet light and heat on the properties of cotton cellulose," Cellulose 1(3), 205-214. DOI: 10.1007/BF0081-3508

Yildirim, N., and Shaler, S. (2017). "A study on thermal and nanomechanical performance of cellulose nanomaterials (CNs)," Materials 10(7), 718. DOI: 10.3390/ma10070718

Yu, H., Qin, Z., Liang, B., Liu, N., Zhou, Z., and Chen, L. (2013). "Facile extraction of thermally stable cellulose nanocrystals with a high yield of $93 \%$ through hydrochloric 
acid hydrolysis under hydrothermal conditions," Journal of Materials Chemistry A, 1, 3938. DOI: 10.1039/C3TA01150J

Zhang, T., Zhang, Y., Wang, X., Liu, S., and Yao, Y. (2018). "Characterization of the nano-cellulose aerogel from mixing CNF and CNC with different ratio," Materials Letters 229, 103-106. DOI: 10.1016/j.matlet.2018.0-6.101

Zu, G., Shen, J., Zou, L., Wang, F., and Zhang, Y. (2015). "Nanocellulose-derived highly porous carbon aerogels for supercapacitors," Carbon 99, 203-211. DOI:

10.1016/j.carbon.2015.11.079

Article submitted: June 28, 2019; Peer review completed: August 26, 2019; Revised version received: September 12, 2019; Accepted: September 27, 2019; Published:

October 10, 2019.

DOI: 10.15376/biores.14.4.9331-9351 